\title{
Electric Properties of Deformable Rubber/CNTs/p-Si Composites under Pressure
}

\author{
Muhammad Tariq Saeed Chani ${ }^{1,2 *}$, Khasan S. Karimov ${ }^{3,4}$, Hadi M. Marwani ${ }^{1,2}$, \\ Mohammed M. Rahman ${ }^{1,2}$, Abdullah M. Asiri ${ }^{1,2}$ \\ ${ }^{1}$ Center of Excellence for Advanced Materials Research, King Abdulaziz University, Jeddah 21589, \\ P.O. Box 80203, Saudi Arabia \\ ${ }^{2}$ Chemistry Department, Faculty of Science, King Abdulaziz University, Jeddah 21589, P.O. Box \\ 80203, Saudi Arabia \\ ${ }^{3}$ Ghulam Ishaq Khan Institute of Engineering Sciences and Technology, Topi-23640, KPK, Pakistan \\ ${ }^{4}$ Center for Innovative Development of Science and Technologies of Academy of Sciences, Rudaki \\ Ave., 33, Dushanbe, 734025, Tajikistan \\ *E-mail: mtmohamad@kau.edu.sa, tariqchani1@gmail.com
}

doi: $10.20964 / 2021.05 .02$

Received: 29 October 2020 / Accepted: 31 January 2021 / Published: 31 March 2021

\begin{abstract}
Rubbing-in technology was used to fabricate the deformable CNT- $p$-Si-rubber nanocomposites. The effect of uniaxial compressive displacement (up to $\sim 6 \%$ of the length of samples) and uniaxial pressure (up to $0.12 \mathrm{kgf} / \mathrm{cm}^{2}$ ) on the I-V characteristics of the samples were investigated. It was obtained that the I-V characteristics under the effect of displacement or pressure are shifted toward increasing currents at permanent applied voltages. The nonlinearity coefficients of the I-V characteristics slightly reduced due to displacement or pressure and increased with applied voltage. It was observed that the investigated composite samples' resistances crucially decreased with increase in compressive displacement or pressure. It may be, first of all, due to the decrease in distances between CNT particles in the composite under compression or pressure and the increase in the cross-section area of the samples, accordingly. The composite samples can be used as deformable and shocked-proof pressure and displacement sensors.
\end{abstract}

Keywords: rubbing-in technology, displacement, uniaxial pressure, non-linearity

\section{$\underline{\text { FULL TEXT }}$}

(C) 2021 The Authors. Published by ESG (www.electrochemsci.org). This article is an open access article distributed under the terms and conditions of the Creative Commons Attribution license (http://creativecommons.org/licenses/by/4.0/). 